\title{
Organocatalysts for enantioselective synthesis of fine chemicals: definitions, trends and developments
}

\author{
Chiara Palumbo* and Matteo Guidotti \\ CNR-Institute of Molecular Sciences and Technologies, Via C. Golgi 19, Milan, Italy \\ *Corresponding author's e-mail address: chiara.palumbo@istm.cnr.it
}

Published online: 17 December 2014 (version 1); 3 March 2015 (version 2); 23 July 2015 (version 3) Cite as: Palumbo C. and Guidotti M., ScienceOpen Research 2015 (DOI: 10.14293/S2199-1006.1.SOR-CHEM.AGZIIB.v3)

Reviewing status: Please note that this article is under continuous review. For the current reviewing status and the latest referee's comments please click here or scan the QR code at the end of this article.

Primary discipline: Chemistry

Keywords: Organocatalysts, Asymmetric synthesis, Fine chemicals, Covalent organocatalysis, Non-covalent organocatalysis Hydrogen-bonding, Organic synthesis

\begin{abstract}
Organocatalysis, that is the use of small organic molecules to catalyze organic transformations, has been included among the most successful concepts in asymmetric catalysis, and it has been used for the enantioselective construction of $\mathrm{C}-\mathrm{C}$, C-N, C-O, C-S, C-P and C-halide bonds. Since the seminal works in early 2000 , the scientific community has been paying an ever-growing attention to the use of organocatalysts for the synthesis, with high yields and remarkable stereoselectivities, of optically active fine chemicals of interest for the pharmaceutical industry. A brief overview is here presented about the two main classes of organocatalysis which are respectively characterized by covalent and non-covalent activation of the substrate. More detailed information about non-covalent interactions for organocatalysis are given. Finally, some successful examples of heterogenisation of organocatalysts are also discussed, in the view of a potential industrial exploitation.
\end{abstract}

\section{INTRODUCTION}

Asymmetric synthesis: the query and the offer

The observation of symmetry and asymmetry in bodies and, in general, in the whole universe is an ancient matter. In the 18th century, Kant wrote that our hands can be thought as mirror images which are not superimposable. The same feature is observed in molecules having a specific property, chirality. The word, firstly introduced in 1904, derives from Greek ' $\chi \varepsilon \tilde{\imath} \rho$ ' ('kheir', eaning 'hand'). The discovery of chirality happened in 1815, with the observation by Jean Baptiste Biot that some molecules could rotate the polarized light plane [1-3].

The occurrence of only one enantiomer of a molecule in nature is connected to the evidence that enantiomers have different biological activity and, in general, they have a different behaviour in a chiral environment [4]. Thus enzymes, receptors and chiral molecules occurring in biochemical transformations interact in a different way with the left-handed or the right-handed enantiomer of a chemical or drug. For instance, some different fragrances are isomers of the same molecule: $(S)-(-)$-limonene (1) smells like turpentine, whereas $(R)-(+)$-limonene (2) smells like lemon (Figure 1a). One can distinguish the two fragrances thanks to our nasal receptors, made of chiral molecules able to recognize the difference between the two enantiomers.

Other examples are molecules used by insects as sexual attractors, pheromones, as well as most of commercialized drugs. Biochemical processes are strongly affected by stereochemical differences, because of the chirality of the involved molecules. A tragic example is thalidomide, a sedative drug which was broadly prescribed to pregnant women since it did not cause dependence (Figure 1b): unfortunately, one of the two enantiomers was responsible for foetus deformities as teratogen agent [5]. Moreover, in this particular case, an additional problem is the in vivo racemization of $(R)$-thalidomide into the $(S)$-thalidomide. So, even if the drug had been commercialized

(a)
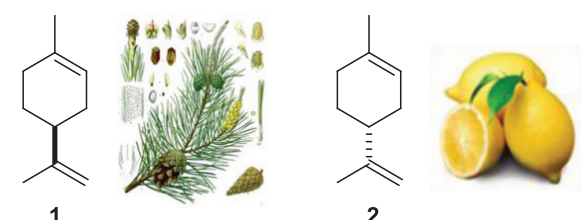

(b)

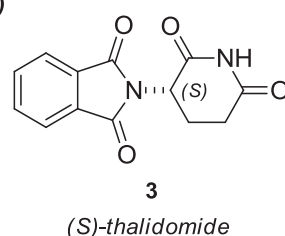

(S)-thalidomide

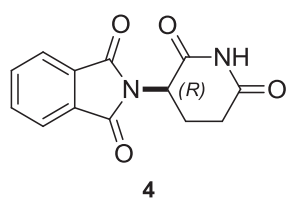

(R)-thalidomide sleep-inducing

Figure 1. (a) Limonene enantiomers and respective different fragrances: turpentine and lemon; (b) thalidomide, the two enantiomers 
as a single enantiomer, it would have been risky because of racemization process. Thus, acceding enantiomerically pure compounds in the development of pharmaceuticals, agrochemicals and flavours is a very significant endeavour, which has been stressed by the US Food and Drug Administration [6].

Among the well-known methods for asymmetric synthesis, catalysis gained an ever-growing success since it presents many advantages with respect to the traditional wasteful stoichiometric methods (chiral auxiliaries, chiral-pool approaches): the catalyst is used at low or very low loading; the starting material does not need to come from the chiral pool; and the synthesis does not require extra steps for the installation and removal of a chiral auxiliary. For these reasons, the chiral catalyst approach has been extensively exploited in the last decades, and many review papers have been written on this topic [7-11]. Furthermore, the chemistry community has strongly believed in the potential of metal-catalyzed transformation, which therefore has been broadly explored through the years leading to remarkable results in the stereoselective synthesis $[12,13]$. Nevertheless, the use of metal-containing catalysts in homogeneous phase has some drawbacks, such as the difficulties and the costs related to the recovering the catalyst. Such disadvantages are overcome heterogeneous catalysis, in which the metal site is supported on or inserted into a solid. The use of enzymes has many attractive features in the context of the Green Chemistry approach but may also have some disadvantages, such as limited stability of enzymes under certain organic reaction conditions and low efficiency when using wild-type strains [14]. Furthermore, the use of highpurity enzymes and, often, of costly co-factors can be a major shortcoming, thus limiting its effective scale-up at commercial level. A more recently developed approach to asymmetric catalysis, based on organic molecules, overcomes some of the issues related to metal-based catalysts and some difficulties connected to the use of enzymes.

\section{Definition and origins of organocatalysis}

The word Organocatalysis has been introduced in the scientific community in 2000 by MacMillan, one of the pioneers of the field $[15,16]$. Organocatalysis refers to the use of small organic molecules to catalyze organic transformations. During the last decades, organocatalysis has been included among the most important and successful concepts in asymmetric catalysis, and it has been used for the enantioselective construction of C-C, C-N, C-O, C-S, C-P and C-halide bonds [17-22]. Furthermore, this new branch experienced a boom in the first eight years from its advent. The publication number conserved the initial trend in the last years and is still growing, with more than 2000 manuscripts published in the field, in which more than 150 reaction types are reported (Figure 2) [23]. In one of his reference work, MacMillan proposed that this big power of attraction could be attributed to the name organocatalysis itself, which provided a strong identity and helped to unify the field [24].

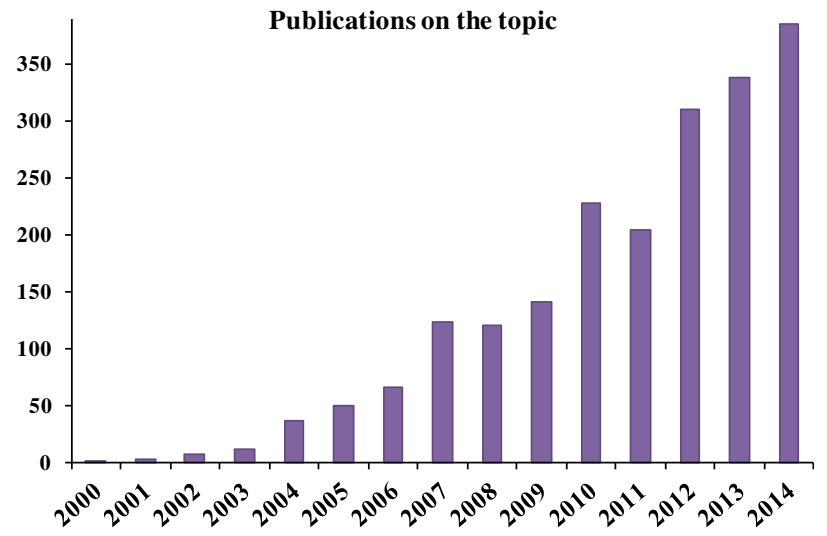

Figure 2. The number of publications on organocatalysis, obtained by searching 'organocatalysis' in Scifinder. For the year 2014, the number has been calculated until December 15th, 2014. See Ref. [23].
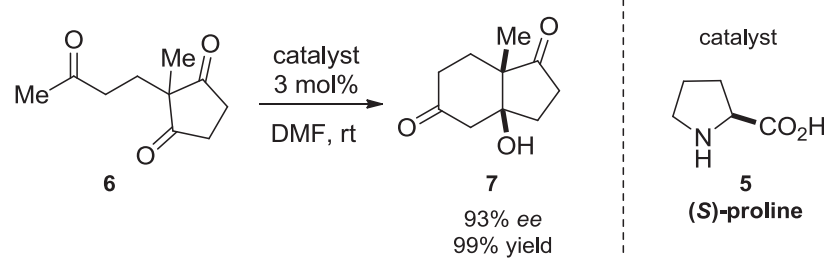

Figure 3. Asymmetric aldol reaction catalyzed by (S)-proline, see Ref. $[27,28]$.

The history of organocatalysis has the special characteristic of being started more than a hundred years ago and actually being ignored as such an important and independent research field until the year 2000. In fact, in 1912, Bredig and Fiske reported that cinchona alkaloid promoted the addition of hydrogen cyanide to benzaldehyde with low enantioselectivity [25] and, in 1960, Pracejus found a cinchona alkaloid catalyzed asymmetric addition of methanol to ketenes [26]. Later, in 1971, Hajos's and Wiechert's groups reported independently the $(S)$-proline-catalyzed asymmetric aldol reaction, without a fully satisfying mechanistic study and without recognizing the important novelty of this finding (Figure 3) [27-29]. It was only in 2000 that Benjamin List reported an asymmetric (S)-proline (5)-catalyzed aldol reaction and officially kicked off to the 'golden age' of organocatalysis, which is the leading topic of this short review.

\section{ORGANOCATALYSIS AND NON-COVALENT INTERACTIONS Activation modes and some exemplar outcomes}

Among the various organocatalytic methodologies, there are different types of activation and two main areas can be identified on the mechanistic basis: (1) covalent organocatalysis and (2) non-covalent organocatalysis [30].

In the former case, within the catalytic cycle, the catalyst covalently binds the substrate, in the latter case only non-covalent 


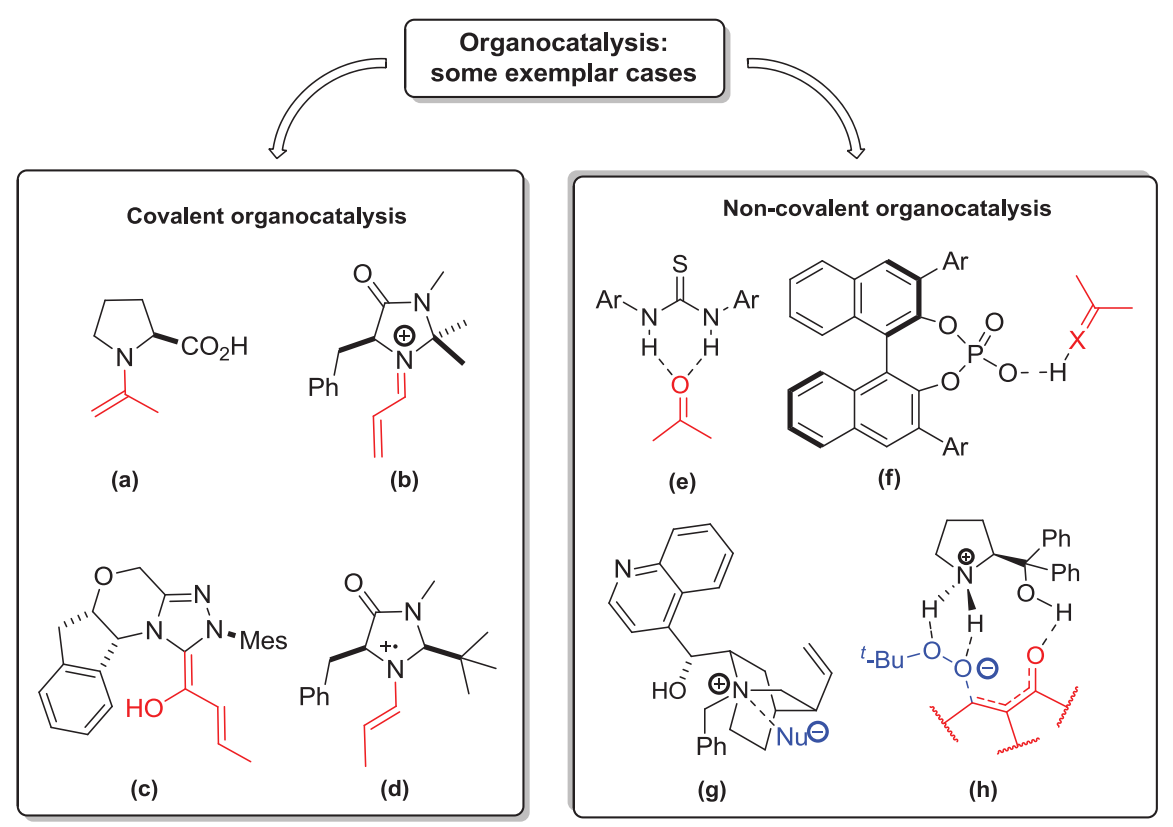

Figure 4. The field of organocatalysis is divided into two main areas, depending on the interactions involved in the mechanism. Some exemplar cases are reported in the Figure.

interactions, such as hydrogen bonding or the formation of ion pairs, activate the molecule towards the asymmetric transformation (Figure 4) [31].

With this brief review contribution, we would like to give a sketchy overview on both types of activation modes, subsequently focusing on some recent outcomes in the field of noncovalent organocatalysis.

\section{Covalent organocatalysis}

In Covalent organocatalysis, it has been ascertained that the catalyst covalently binds the substrate, as depicted in the examples presented in Figure 4. Many classes of covalent organocatalysis can be listed, such as enamine (a), iminium ion (b), $\mathrm{N}$-heterocyclic carbene (c), singularly-occupied molecular orbital (SOMO) (d), and others. Further reviews on several aspects of organocatalysis can be found in the literature $[32,33]$. In this brief text, some examples of the first two activation modes are described, in order to give a hint of the potential of organocatalysis. In the enamine catalysis, a catalytically generated enamine intermediate is formed via deprotonation of an iminium ion and it reacts with various electrophiles or undergoes pericyclic reactions. Typical examples are proline-catalyzed aldol reactions which proceed via enamine intermediates, such as the one reported by List in 2000. The hypothesized mechanism involves the formation of the enamine between $(S)$-proline and acetone; $(S)$-proline is in fact able to increase the HOMO energy, and thus the reactivity, of the nucleophile. Specifically, in the reaction intermediate, the catalyst interacts with the aldehyde through the protonation of the carbonyl, leading to a deep stereocontrol. This
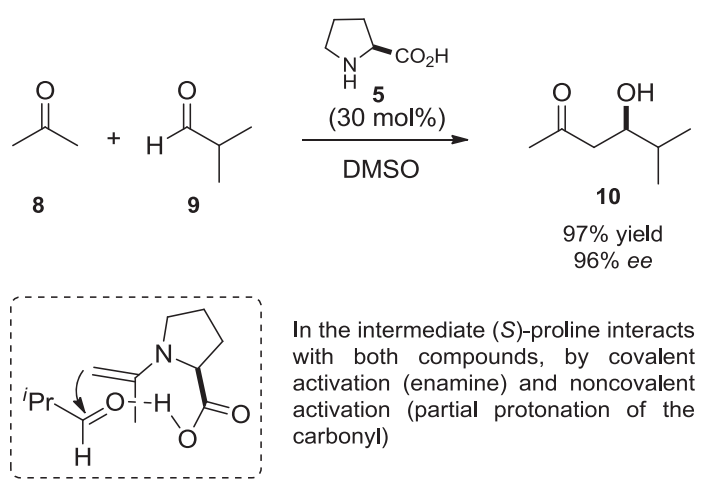

In the intermediate $(S)$-proline interacts with both compounds, by covalent activation (enamine) and noncovalent activation (partial protonation of the carbonyl)

Figure 5. Direct aldol reaction catalyzed by (S)-proline, see Ref. [34]

pioneering reaction allowed the attainment of highly enantioenriched aldols in very good yield (Figure 5) [34].

Another example of catalysis based on the enamine mechanism is the asymmetric synthesis of a high added-value molecule, such as oseltamivir (commercially also known as Tamiflu), which is based on simple starting materials, such as alkoxyaldehyde 12, nitroalkene 14 and diethyl vinylphosphonate derivative 15 (Figure 6) [35]. The first reaction, catalyzed by the trimethylsilyl-protected prolinol 11, is the organocatalytic enantioselective reaction between 12 and 14, giving a Michael adduct. This adduct then reacts in the next step with 15 to give, after a Wittig reaction and a thio-Michael reaction, the intermediate 16, from which enantiopure oseltamivir $\mathbf{1 7}$ is achieved in $57 \%$ overall yield. This reaction sequence proceeds by three distinguished one-pot operations and only one 


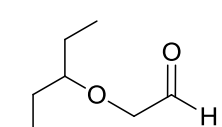

12

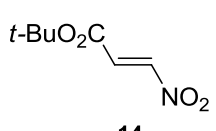

14

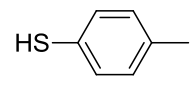

13

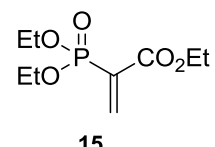

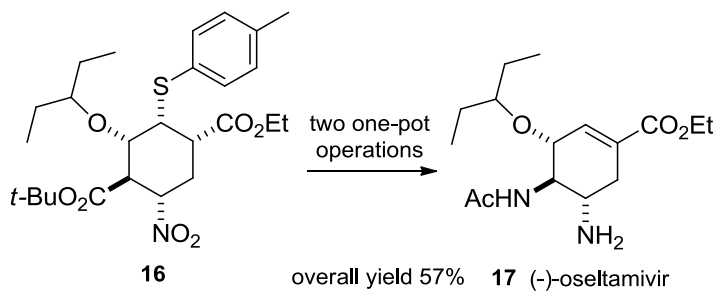

16

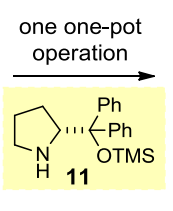

Figure 6. Oseltamivir enantioselective synthesis, see Ref. [35].

(a)

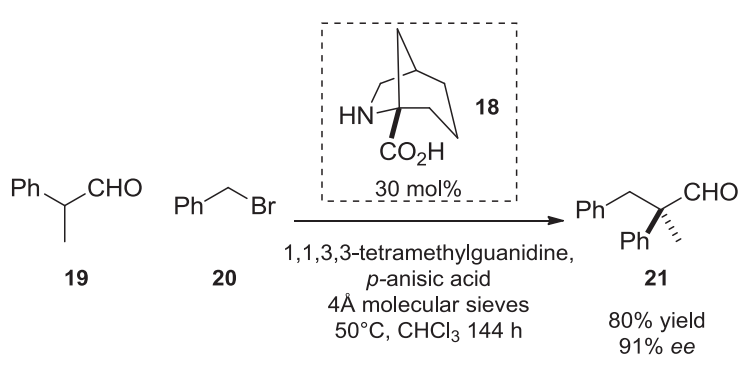

(b)

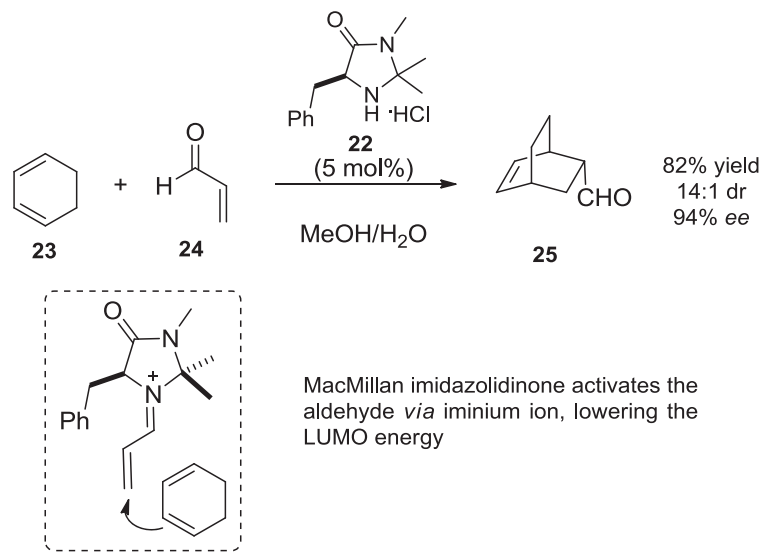

Figure 7. (a) Asymmetric alkylation of $\alpha$-branched aldehydes catalyzed by secondary amine 18; (b) direct Diels-Alder reaction catalyzed by MacMillan imidazolidinone 22 .

column chromatography purification, and it is the most efficient synthesis of oseltamivir reported so far [36].

An additional noteworthy application of enamine catalysis is the first catalytic asymmetric $\alpha$-alkylation of $\alpha$-branched aldehydes developed by List et al. starting from simple racemic $\alpha$-branched aldehydes and achieving the corresponding enantiomerically enriched products, in a dynamic kinetic asymmetric transformation [37]. In this reaction, racemic aldehydes are converted into corresponding enantioenriched alkylated products in high yields, up to $80 \%$ (Figure 7a). Furthermore, the reaction features a new sterically demanding proline-derived catalyst (18), which the authors hypothesize to be exploited in other asymmetric transformations in the future.

In iminium catalysis, the active species is an iminium ion formed by the reversible reaction of an amine catalyst with a carbonyl substrate (Figure 7b). The higher reactivity of the iminium ion compared to the carbonyl species is utilized to facilitate reactions such as cyclo- and nucleophilic additions.

In 2000, MacMillan presented a direct Diels-Alder reaction catalyzed by a new chiral imidazolidinone catalyst (22). This catalyst is able to direct the addition of a diene to enals, by lowering the energy of the lowest unoccupied molecular orbital, LUMO, thus activating the dienophile towards the diene addition (Figure $7 \mathrm{~b}$ ) [15, 16]. These organocatalytic reactions paved the way to many research teams that started to work in the same field, thus developing many different catalyst types and contributing to the growth of the application potential for organocatalysis.

For the enantioselective epoxidation of $\alpha$ and $\beta$-branched enals, Hayashi's and Jørgensen's groups independently disclosed the remarkable potential of $\alpha, \alpha$-diaryl prolinol silyl ethers (30 and 31, Figure 8a, 8b), obtaining the desired epoxide in high enantioselectivities (up to $98 \%$ ee) and excellent yields (up to 90\%) [38, 39]. Furthermore, both groups investigated on the reaction mechanism, hypothesizing an iminium ion covalent catalysis. In fact, within the catalytic cycle, the key intermediate is an iminium ion (I), which lowers the LUMO energy of the electrophilic double bond of the substrate. The subsequent stereoselective addition of the hydroperoxide anion, followed by the cyclization, leads to the enantioenriched product (Figure 8c) [40]. The understanding of the mechanisms for covalent organocatalysis is growing, and an ever-increasing number of evidences highlight that the reactivity in organocatalytic reactions is often influenced and modulated by secondary non-covalent interactions [41].

\section{Non-covalent organocatalysis}

Non-covalent organocatalysis has recently been explored by many research groups and a vigorous development in this area has been achieved as well [42]. This kind of catalysis is commonly attributed to either hydrogen bond network or ionpairs formation.

To be more precise, as recently elucidated by Jacobsen, many different interactions are often cooperating within the reaction mechanism in order to lead to high enantioselectivities [43]. The known non-covalent interactions scope includes 
(a)

$$
\text { (b) }
$$

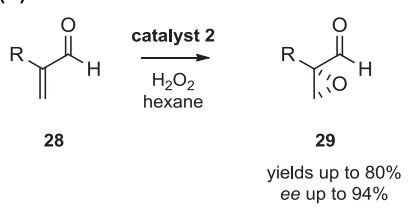

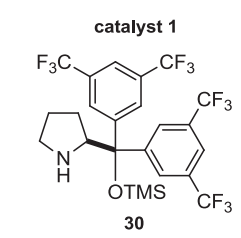

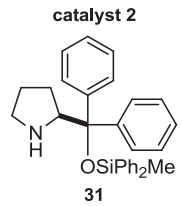

(c)

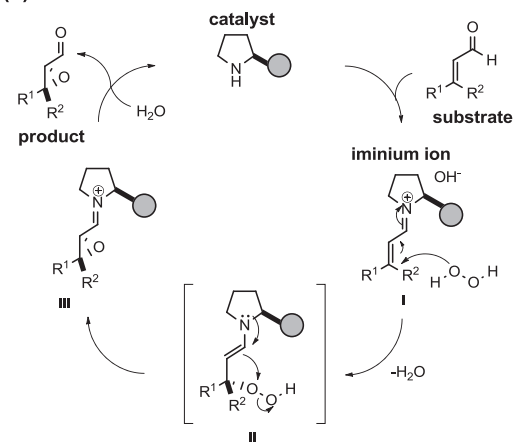

Figure 8. Two examples of catalytic enantioselective epoxidation of enals. (a) from Ref. [38], (b) from Ref. [39] and (c) hypothesized mechanism.
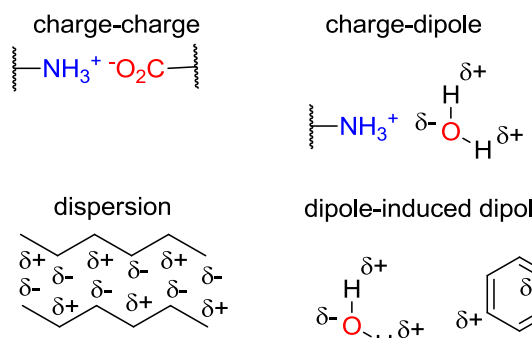

dipole-induced dipole
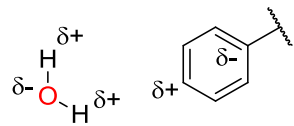

dipole-dipole
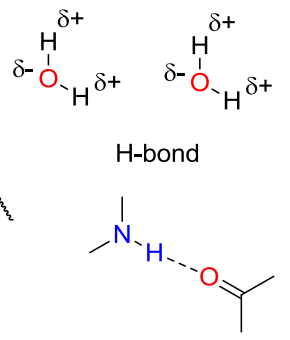

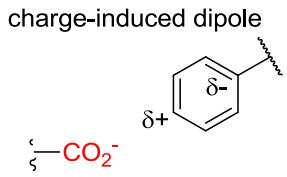

steric repulsion

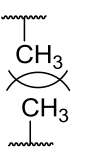

Figure 9. Possible non-covalent interactions, see Ref. [43].

charge-charge, charge-dipole, dipole-dipole, charge-induced dipole, dipole-induced dipole forces, steric repulsion and H-bond (Figure 9).

Indeed non-covalent interactions are weaker and less directional with respect to covalent bonding. Thus, in order to get the same performance in terms of stereoselectivity, more than one interaction is requested in order to have an effective spatial constraints. In fact, this kind of catalysts enclose more than one functionality, such as H-bond donor or acceptors or acid/basic sites, capable of generating multiple weak interactions, although operating in a synergistic way. For this reason, many of such catalysts are also called bifunctional. Noteworthy examples of bifunctional non-covalent organocatalysts are the Soós thiourea (32) and diphenyl prolinol (33), depicted in Figure 10 [44]. Both of these catalysts bear H-bond donor groups and a Brønsted base functionality [45]. The different functionalities are supposed to cooperate within the reaction mechanisms in many cases, activating both electrophile (through the Lewis acid [LA]) and nucleophile (through the Brønsted base) (Figure 10) [46-48].

\section{Explicit H-bonding organocatalysis}

One refers to explicit H-bonding organocatalysis when the activation mode clearly relies on $\mathrm{H}$-bond interactions, even

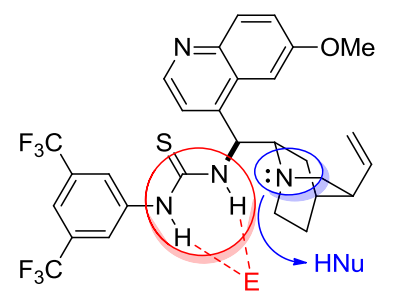

32

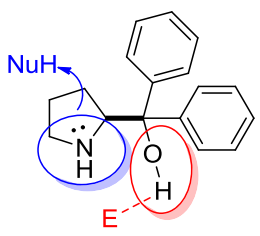

33

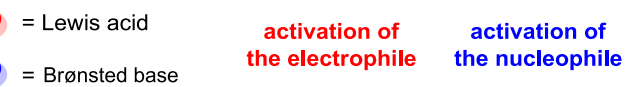

Figure 10. Examples of bifunctional, non-covalent organocatalysts.

though other secondary interactions may usually cooperate with them. For instance, Jacobsen's and Schreiner's thioureas $(34,35$, Figure 11) are paradigmatic cases for this class of organocatalysts $[49,50]$. They clearly resemble the enzymatic pockets found in serine proteases for the activation of the amide carbonyl towards the serine nucleophilic attack. Within what is called the 'oxyanion hole', the amide carbonyl is coordinated and activated by two NH groups, hence favouring the serine nucleophilic attack with the formation of a tetrahedral intermediate stabilized by H-bonding (Figure 11) 
(a)
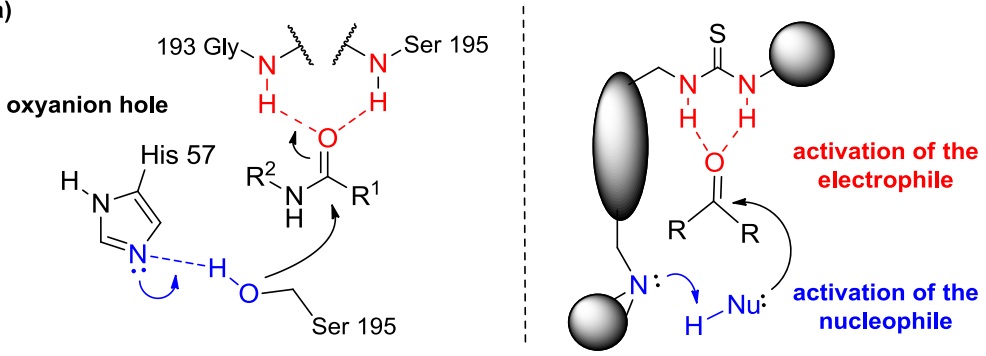

(b)

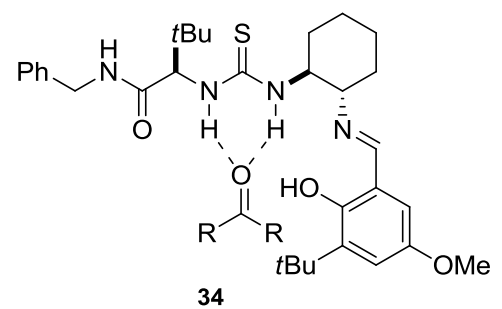

Jacobsen thiourea<smiles>[R]C([R])=COC(=O)Nc1cc(C(F)(F)F)cc(C(F)(F)F)c1</smiles>

Schreiner thiourea

Figure 11. (a) The so-called 'oxyanion hole' in serine protease activating a carbonyl; (b) hydrogen bonding organocatalysts activating a carbonyl.

(a) Claisen rearrangement

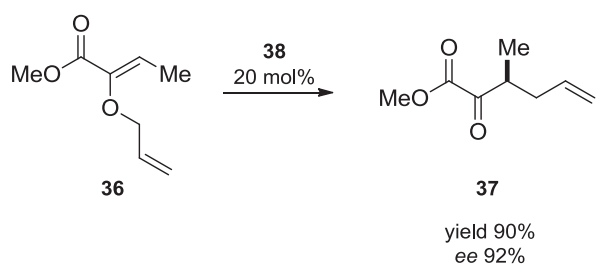

(b) Pictet-Spengler cyclization

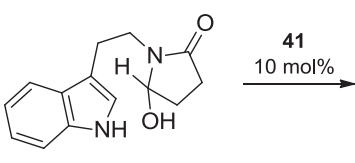

39

(c) imine hydrocyanation

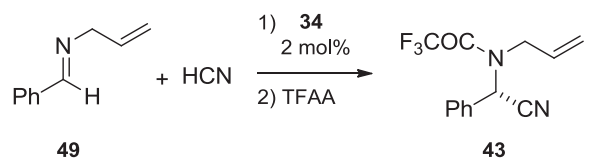

49

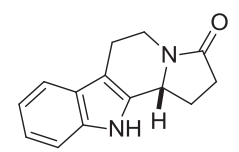

40

yield $90 \%$ ee $97 \%$

ee $91 \%$

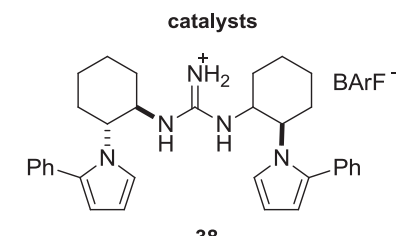

38

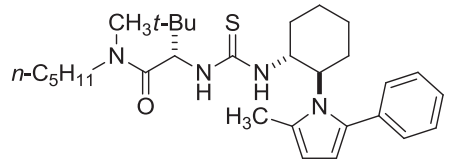

41

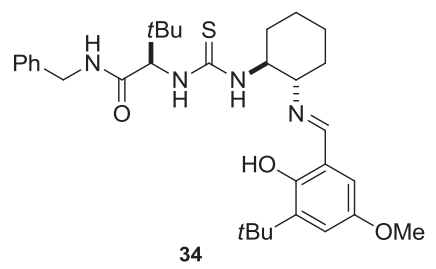

Figure 12. Examples of reactions catalyzed by $\mathrm{H}$-bonding catalysts $(38,41,34)$ depicted on the right:: (a) from Ref. [55], (b) from Ref. [56], (c) from Ref. [57].

$[51,52]$. A variety of electrophiles can be activated towards nucleophilic asymmetric addition with the same action mode, and a series of reactions have been investigated so far $[53,54]$ Moreover, H-bonding catalysts can promote enantioselective reactions by stabilizing anionic fragments, as in Claisen rearrangement, by binding an anion, as in Pictet-Spengler cyclization and hydrocyanation of imines (Figure 12) [55-57]. In all of these cases, very good enantioselectivities are reported (up to $97 \%$ ee for instance in the Pictet-Spengler), thus verifying the potentialities of H-bond. 

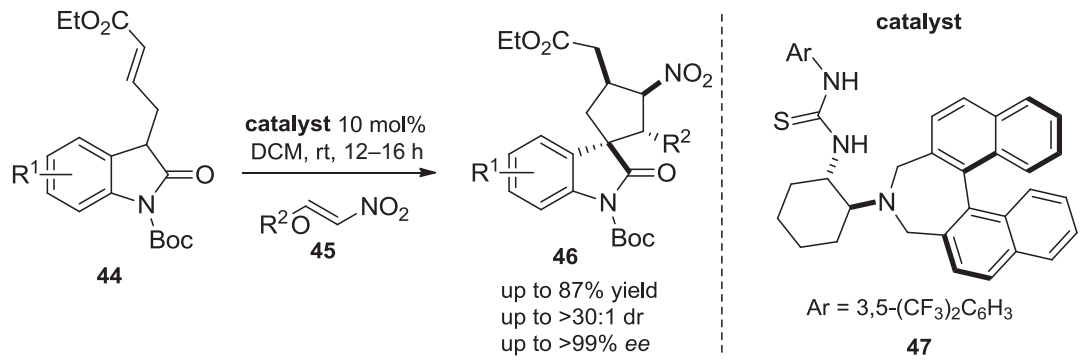

Figure 13. Thiourea catalyzed enantioselective synthesis, from Ref. [58].

Regarding the classification of hydrogen bonding catalysts within the Lewis/Brønsted acid/base catalysis branches, Schreiner and co-workers performed some pioneering studies concerning thioureas as H-bonding additives, by means of NMR, IR and computational techniques. The reactivity of these systems, in a Diels-Alder reaction, was also compared to the one recorded over two widely used LAs (aluminium trichloride, titanium tetrachloride). These studies proved that many similarities are present between LAs and hydrogen bonding catalysts. This is the reason why some hydrogen bonding catalysts can be classified as LAs [44].

A noteworthy example was reported in 2011 by Shao and coworkers who has developed an organocatalytic asymmetric double Michael addition of nitroalkenes 45 to 3-substituted oxindoles 44. This transformation, catalyzed by a thiourea catalyst (47) under mild conditions, leads to spirocyclopentaneoxindoles (46) with quite good diastereoselectivity and enantioselectivity (up to $>30: 1 \mathrm{dr}$; up to $>99 \%$ ee) (Figure 13) [58]. The great potential of chiral thioureas has been recently employed in other asymmetric transformations $[59,60]$.

Another significant organocatalyst is the (S)-2-diphenylhydroxymethylpyrrolidine 33, which has been thoroughly exploited in organocatalysis. The first report about enantioselective catalytic reactions promoted by this chiral prolinederived molecule dates back to 2000, and it is applied to the epoxidation of alkenes. In the patent, it has been verified that the epoxidation of unfunctionalized alkenes can proceed efficiently and enantioselectively using prolinol $\mathbf{3 3}$ or other simple amines as catalysts and without the need for metal complex catalysts, in the presence of an oxidizing agent [61]. This patent was followed by several papers. Some examples are enantioselective reductions [62], asymmetric heteroDiels-Alder of aldehydes with enones [63] and self-aldol reaction, all of them being enamine-mediated [64]. Remarkably, diarylprolinols have shown promising performances in non-covalently activated reactions as well, and recent advances have been recently reviewed [65]. For instance, diphenylprolinol 33 and diarylprolinols, 55 and 56, have been employed the enantioselective conjugate addition of N-heterocycles to $\alpha, \beta$-enones (Figure 14a), and in the epoxidation of electron deficient olefins, such as enones acrylonitriles (Figure 14b), and useful building blocks such as $\alpha$-ylidenoxindoles (Figure 14c) [66-70]. For the first organocatalytic addition of benzotriazole (49) to the enone 48 , the authors hypothesize a hydrogen bond network acting in the transition state towards the induction of a moderate enantioselectivity in the subsequent formation of the product 50. The group of Lattanzi in the last decade achieved very good results in the epoxidation of electron deficient alkenes, such as enones and acrylonitriles, in addition to some elucidations on the reaction mechanism, which confirm the hypothesis of a hydrogen bond catalysis [71]. Furthermore, some interesting results have been achieved in the epoxidation of $\alpha$-ylidenoxindoles, which are electron-poor alkenes bearing an oxindole core. This moiety is quite often retrieved in biologically active molecules, such as some anticancer agents. The organocatalytic epoxidation of such alkenes, through a non-covalent activation mode, in the presence of diphenylprolinol 33, as catalyst, and tert-butylhydroperoxide, TBHP, as oxidizing agent, leads to the formation of enantioenriched spiroepoxy oxindoles (ee up to $82 \%$, for compound 54). The reaction mechanism involves a transition state in which catalyst, substrate and oxidant are inserted in a hydrogen network, thank to the two hydrogen bonding donor groups positioned on the catalyst, that are the amine and the hydroxyl.

\section{Brønsted acid catalysis}

Chiral Brønsted acids (BAs) have in the last decades proved to be excellent organocatalysts, since they can catalyze a number of chemical transformations, leading to highly enantioenriched products. The substrate activation by BA is related to, though different from, H-bonding catalysis, since normally the formation of a hydrogen bond precedes the transfer (partial or complete) of a proton. Moreover, some recent studies about BA-catalyzed imine activation suggest that besides ion pairing, due to the protonation of the substrate, hydrogen bonding exists. This is a proof of the tight connection between $\mathrm{H}$ bonding and BA catalysis. Before this study, it was assumed that full protonation of the imine resulted in the formation of an ion pair [72]. It is well known that BAs could operate by means of specific or general acid catalysis [73, 74]. In specific BA catalysis, the electrophilic substrate is reversibly protonated in a pre-equilibrium step, prior to the nucleophile attack (II, Figure 15a). Conversely, in general BA catalysis, the proton is (partially or fully) transferred in the transition state of the rate-determining step (I, Figure 15a). In the activation of a 
(a)

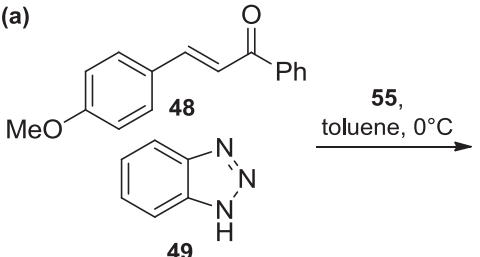

(b)

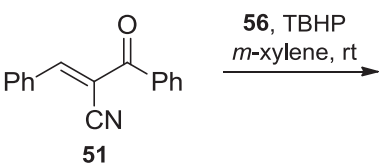

(c)

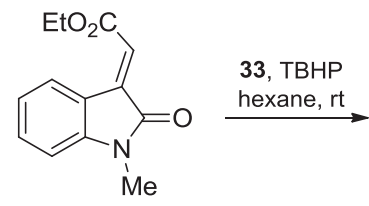

53

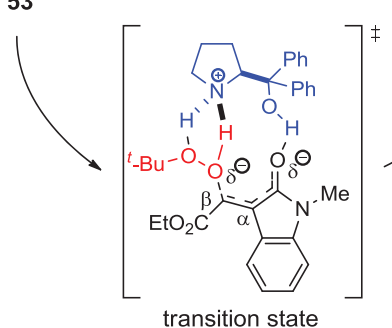

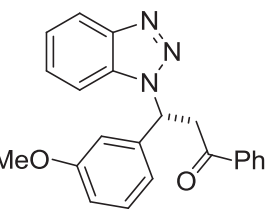

$5034 \%$ ee
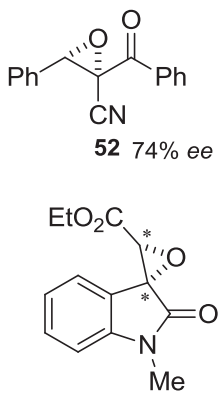

$5482 \%$ ee

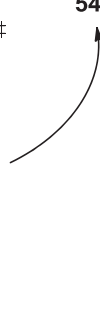

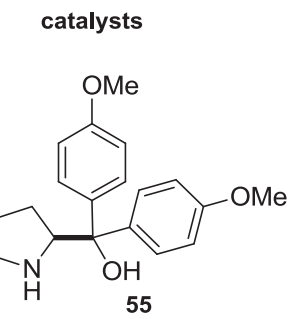
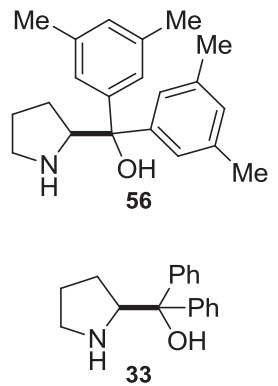

Figure 14. Enantioselective conjugate addition of $\mathrm{N}$-heterocycles to $\alpha, \beta$-enones (a), from Ref. [67]; epoxidation of acrylonitriles (b), from Ref. [69]; epoxidation of $\alpha$-ylidenoxindoles (c), from Ref. [70].

compound, e.g. carbonylic derivative, towards chemical transformations, BAs differ in the catalytic centre from the wellknown LAs. Indeed, in BA the centre is a proton instead of a metal and this goes along with the Green Chemistry principles (Figure 15b) [75]. However, proton has only one valence orbital, limiting the possible interactions. As a consequence, the BA catalyst scaffold should be sterically hindered in order to induce stereocontrol [76].

Chiral BA catalysis has had a breakthrough in asymmetric organocatalysis in 2004, when Terada and Akiyama independently presented an enantioselective Mannich-type reaction catalyzed by new metal-free phosphoric acid, BINOL-derived compounds, such as $\mathbf{6 1}$ (Figure 16a) [77, 78]. These pioneering studies showed how powerful could be the use of BA catalysis for asymmetric synthesis. BINOL-derived catalysts are designed in order to get an environment both sterically demanding and moderately acid, in order to achieve good enantioselectivity and to protonate the imine nitrogen [79]. While the first studies do not elucidate the specific mechanistic pathway (even though they suggest the protonation of the imide by the phosphoric acidic site), later on, the BA catalytic activity came up. Phosphoric acids bear an acidic site $(\mathrm{OH}$, Figure $15 \mathrm{c})$ and a basic site $(\mathrm{P}=0$, Figure $15 \mathrm{c})$ on the same acidic species, allowing the simultaneous activation of a nucleophile and of an electrophile. In the wake of the first encouraging attainments, in the last decade many different types of chiral phosphoric acids have been synthesized and employed in a broad scope of enantioselective reactions. It is in this context that List and co-workers paid particular attention onto chiral BA catalysts, developing a wide set of chiral phosphoric acids, whose utility is well recognized. The (S)-TRIP (57, Figure 15c), a binaphtyl phosphoric acid, is the most relevant example of this series since it has been employed for a broad range of reactions showing excellent results in terms of enantioselectivity. Noteworthy examples are Povarov reactions, 0 -alkylations, Pictet-Spengler reactions or benzidine rearrangement [80-83]. Chiral BAs have shown particularly successful performances in the acetalization reaction [84-86]. In 2005, Antilla et al. reported about the amidation of imines, which consists of a $\mathrm{N}, \mathrm{N}$-acetalization. The reaction, catalyzed by catalyst $\mathbf{6 4}$, under mild conditions, is very efficient and selective, although with a narrow substrate scope (Figure 16b) [87]. A recent application is in the intermolecular allylic amination of allylic alcohols catalyzed by a phosphoramide, which leads to a variety of optically active allylic amines in good yields and ee values up to $94 \%$ [88]. The paper highlights that the amination site is mainly determined by electronic effects, and the reaction is supposed to occur at the carbon adjacent to the electron-rich 
(a)
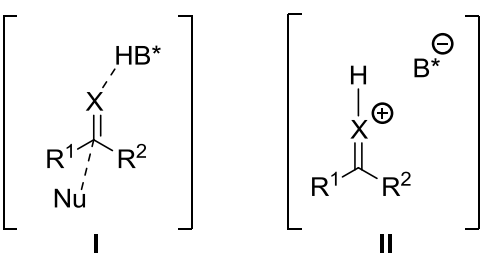

(b)

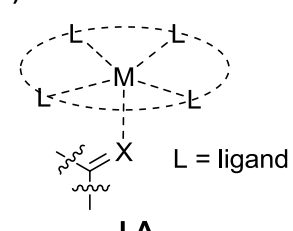

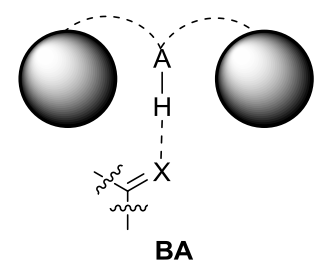

(c)
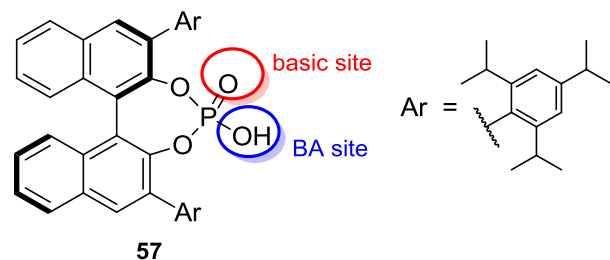

(S)-TRIP

Figure 15. (a) Transition states in general acid catalysis (I) and in specific acid catalysis (II); (b) Lewis acid (LA) and Brønsted acid (BA) catalysts; (c) (S)-TRIP [(S)-3,3'-bis(2,4,6-triisopropylphenyl)1,1'-binaphthyl-2,2'-diyl hydrogen phosphate].

aryl group owing to a carbocation intermediate involved in the process.

A fascinating application of chiral BA catalysis is the synthesis of helicenes applying the Fischer indolization (Figure 16c) [89]. The helical chirality strongly attracts attention in very diverse fields, such as material sciences, catalysis and biology. The authors could induce the stereochemistry of the helicene by means of a peculiar catalyst 68, derived from SPINOL $\left((S)-1,1^{\prime}\right.$-spirobiindane-7,7'-diol) which bears extended $\pi$-substituents interacting with the substrate via $\pi-\pi$ interactions $[90,91]$.

In 2012, List et al. developed a new concept: confined BAs, extremely, sterically demanding and bearing a chiral pocket that resembles the one found in enzymes [92]. These catalysts have been initially used for the asymmetric spiroacetalization of sterically non-hindered compounds, in order to obtain biologically relevant spiro-acetals, such as olean (major sex pheromone of the olive fruit fly; Figure 17), with very high enantiomeric excesses $(96 \% e e)$. The new imidophosphoric acid still bears the double functionality, acid and base, on the two phosphates, allowing small and unhindered molecules to enter the active pocket and to be activated in such a peculiar environment towards the chemical transformation. This pioneering work paved the way to other enantioselective transformations, such as sulfoxidation and acetalization, verifying further the potential of confined BA [93, 94].

\section{HETEROGENIZATION OF ORGANOCATALYSTS}

Taking into account that the organocatalysts are in homogeneous phase together with the rest of the reactants involved in the reactions and that their chemical nature is often comparable to the nature of the products, a proper separation and purification of the desired compounds can be tricky and sometimes difficult. However, the recovery and the reuse of the catalyst is not necessarily one of the major issues, at least at laboratory scale, and the catalytically active species are often used in only one run. At larger scale, all these factors can be a hurdle in the set-up of a commercial industrial process based on these systems. So, in the last years, envisaging some industrial uses for organocatalysts, a few attempts of anchoring them over solid supports have been made. In order to implement the concepts of Green Chemistry, the heterogeneous catalysts should be recyclable, selective, robust, cheap and more active than their homogeneous analogues [95]. However, the anchoring of active homogeneous catalysts on solid supports may lead to less selective species. A fascinating example in this context is a recent invention by Lee et al., which makes use of nylon textiles as supports for organocatalysts [96, 97]. These new catalysts, OrganoTexCat (Figure 18), have been synthesized starting from the corresponding organocatalyst, exploiting the production of radicals on the nylon surface, induced by the irradiation under ultraviolet light. OrganoTexCat displays excellent stability, activity and recyclability and has been used for some organic transformations. For instance, the silylated glutamic anhydride (a valuable statin derivatives precursor) has been converted into compound $\mathbf{7 3}$, in a gram scale, in excellent yield and selectivity. The reaction has been performed by means of a continuous iterative reaction, which was performed in a continuous circle reactor, equipped with a column packed with the OrganoTexCat $\mathbf{7 4 .}$

Another noteworthy example of supported organocatalyst is the one developed by Raja and co-workers [98]. They have illustrated the covalent heterogenization of two homogeneous organocatalysts, cinchonine and 1,4-diazabicyclo[2.2.2] octane, onto the inner walls of mesoporous silica supports. This resulted in highly active, selective, recoverable solid catalysts, which were employed in the Michael addition reaction depicted in Figure 19. Some other successful examples of enantioselective transformations by immobilized organocatalysts are reported in the very recent literature [99-102].

\section{CONCLUDING REMARKS}

What lies ahead? From the number of publications, it is possible to affirm that organocatalysis is not experiencing a slowdown, presumably because many scientists have realized that its peculiarities and benefits can be exploited further and even enhanced. Organocatalysis can be therefore considered an additional tool for asymmetric synthesis, besides other kinds of well-established catalytic methods. Many patents have already been disclosed on enantioselective 
a)<smiles>COC(OC)=C(C)[C+]1C=CC(O)C(N=Cc2ccccc2)=C1</smiles>

58

59 b)

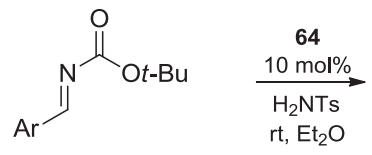

62

$\mathrm{Ar}=4-\mathrm{CF}_{3} \mathrm{C}_{6} \mathrm{H}_{4}$

c)<smiles>NN(P)c1ccc2ccccc2c1</smiles>

65<smiles>O=C1CCc2ccc3ccc4ccccc4c3c2C1</smiles>

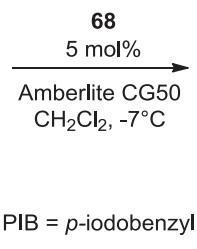

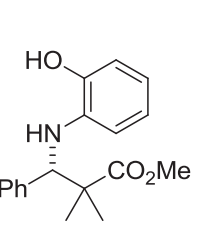

60

$99 \%$ yield $89 \%$ ee

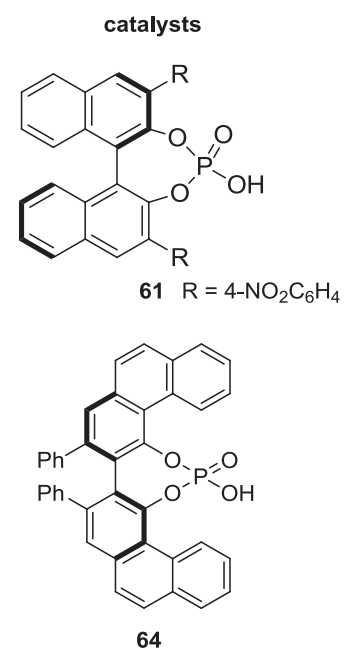

64

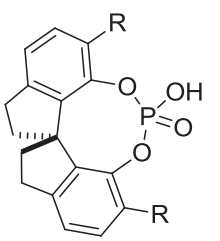

$68 \mathrm{R}=1$-pyrenyl

Figure 16. (a) Enantioselective Mannich-Type reaction, from Ref. [77, 78]; (b) Brønsted acid catalyzed imine amidation, from Ref. [87]; (c) Fischer indolization, from Ref. [89].

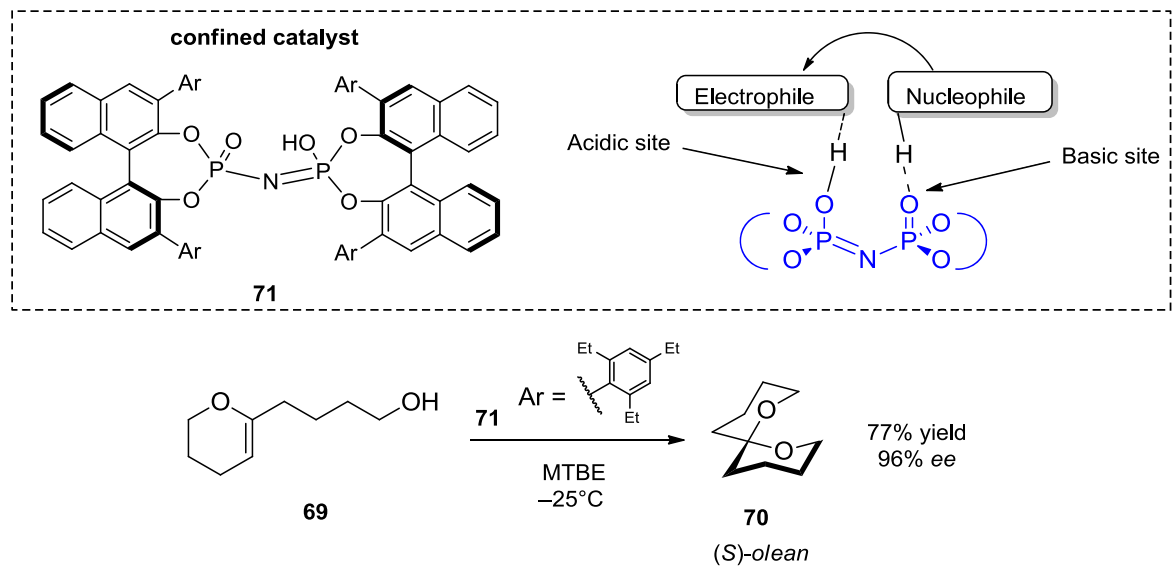

Figure 17. The asymmetric spiroacetalization reaction catalyzed by confined Brønsted acids (BAs); bifunctional confined catalysts' pocket, from Ref. [92].

organocatalytic transformations, and this is a clear clue of the relevant potential of the technique [103-106]. Furthermore, a few organocatalytic procedures have recently been extended to industrial plants, even though the scale-up of a reaction is not straightforward [107, 108]. For instance, the well-known L-proline-catalyzed intramolecular aldol reaction (i.e., the Hajos-Parrish-Sauer-Wiechert process, see Figure 3) has been implemented by two companies, Schering and Hoffman-La Roche for the asymmetric synthesis of steroids on multi-kilogram scale [27, 28]. We could cite many other examples of industrial applications of homogeneous organocatalysis, even though still some industrial manufacturers are reluctant in considering it as an alternative to classical methods [109]. 

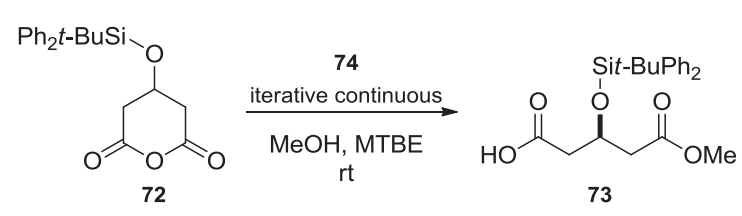

$11 \mathrm{~h}, 1 \mathrm{~g}$ scale $(>10$ times) $>99 \%$ yield up to $94 \%$ ee

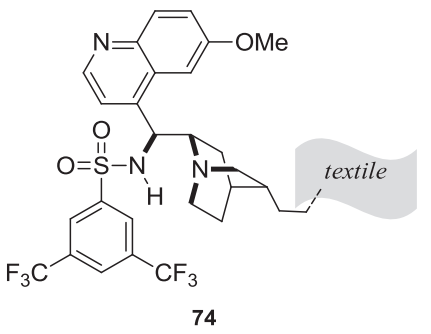

Figure 18. 'OrganoTexCat' for the desymmetrization of silylated glutamic anhydride, from Ref. [96, 97]. The reaction is performed under continuous conditions, in a flow reactor packed with 74 .
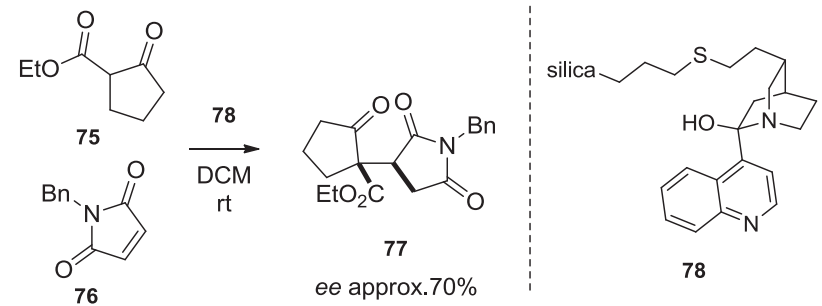

Figure 19. Enantioselective Michael addition, from Ref. [98].

However, it is envisaged that the immobilization of a wide scope of organocatalysts will follow soon, with improvements in terms of purification of the products, recyclability of the catalyst, and sustainability of the process, and the use of heterogeneous systems will help the fulfilment of a broader industrial exploitation. Indeed, thanks to a trans-disciplinary approach, merging the know-how in the field of catalysis, organic synthesis, materials science and macromolecular chemistry, it is possible to immobilize spatially confined highly selective organocatalysts, in order to obtain effective and stable artificial analogues of enzymes that are free from transition-metal active centres. This paves the way to enantioselective enzymomimetic catalysts with an enhanced robustness and with a better capability to withstand the severe reaction conditions of conventional industrial synthesis, with respect to their counterparts from biological origin.

\section{ACKNOWLEDGEMENTS}

We gratefully acknowledge Regione Lombardia for a fellowship to C. P. within the SusChemLombardia Project (framework Agreement CNR - Region Lombardy 2013-2015). Furthermore we are thankful to Dr T. Gasperi, Prof. M. A. Loreto and Prof. Dr B. List for the possibility to be inspired by organocatalysis.

\section{REFERENCES}

[1] Hoffmann R. The same and not the same. New York (NY): Columbia University Press; 1995.

[2] Biot JB, Bull Soc Philomath. 1815, Paris, 190.
[3] Aitken RA, Kilényi SN. Asymmetric synthesis. London: Blackie Academic and Professional; 1992.

[4] Noyori R. Asymmetric catalysis: science and opportunities (Nobel Lecture). Angew Chem Int Ed. 2002;41(12):2008-22. doi:10.1002/1521-3773(20020617)41:12<2008::AIDANIE2008>3.0.CO;2-4

[5] Blaschke G, Kraft HP, Fickentscher K, Köhler F. Chromatographic separation of racemic thalidomide and teratogenic activity of its enantiomers. Arzneim-Forsch. 1979;29:1640.

[6] Stinson SC. Chiral drugs: in wake of new FDA guidelines, most drug firms are developing single enantiomers, spawning a "chirotechnology" industry. Chem Eng News. 1992;70(39):4679. doi:10.1021/cen-v070n039.p046

[7] Cahard D, Bizet V. The influence of fluorine in asymmetric catalysis Chem Soc Rev. 2014;43(1):135-147. doi:10.1039/ C3CS60193E

[8] Matsunaga S, Shibasaki M. Recent advances in cooperative bimetallic asymmetric catalysis: dinuclear Schiff base complexes. Chem Commun. 2014;50(9):1044-1057. doi:10.1039/ C3CC47587E

[9] Carthy M, Guiry PJ. Axially chiral bidentate ligands in asymmetric catalysis. Tetrahedron. 2001;57(18):3809-3844. doi:10.1016/ S0040-4020(01)00087-4

[10] Jacobsen EN. Asymmetric catalysis of epoxide ring-opening reactions. Acc Chem Res. 2000;33(6):421-31. doi:10.1021/ $\operatorname{ar} 960061 \mathrm{v}$

[11] Federsel H-J. Asymmetry on large scale: the roadmap to stereoselective processes. Nat Rev Drug Discov. 2005;4 (8):685-97. doi:10.1038/nrd1798

[12] Zhou S, Fleischer S, Jiao H, Junge K, Beller M. Cooperative catalysis with iron and a chiral brønsted acid for asymmetric reductive amination of ketones. Adv Synth Cat. 2014;356 (16):3451-55. doi:10.1002/adsc.201400328

[13] Kolb HC, VanNieuwenhze MS, Sharpless KB. Catalytic asymmetric dihydroxylation. Chem Rev. 1994;94(8):2483-547. doi:10.1021/cr00032a009

[14] Klibanov AM. Asymmetric transformations catalyzed by enzymes in organic solvents. Acc Chem Res. 1990;23(4):11420. doi:10.1021/ar00172a004

[15] Ahrendt KA, Borths CJ, MacMillan DWC. New strategies for organic catalysis: the first highly enantioselective organocatalytic Diels-Alder reaction. J Am Chem Soc. 2000;122 (17):4243-44. doi:10.1021/ja000092s

[16] Jen WS, Wiener JJM, MacMillan DWC. New strategies for organic catalysis: the first enantioselective organocatalytic 1,3-dipolar cycloaddition. J Am Chem Soc. 2000;122(40): 9874-75. doi:10.1021/ja005517p

[17] Chauhan P, Mahajan S, Enders D. Organocatalytic carbonsulfur bond-forming reactions. Chem Rev. 2014;114(18):880764. doi: $10.1021 / \mathrm{cr} 500235 \mathrm{v}$ 
[18] Rueda-Becerril M, Mahé O, Drouin M, Majewski MB, West JG, Wolf MO, Sammis GM, Paquin J-F. Direct C-F bond formation using photoredox catalysis. J Am Chem Soc. 2014;136 (6):2637-41. doi:10.1021/ja412083f

[19] Carlone A, Bartoli G, Bosco M, Sambri L, Melchiorre P. Organocatalytic asymmetric hydrophosphination of $\alpha, \beta$-unsaturated aldehyde. Angew Chem Int Ed. 2007;46(24):4504-06. doi:10.1002/anie.200700754

[20] Barrulas P, Benaglia M, Burke AJ. Synthesis of novel cinchonaamino acid hybrid organocatalysts for asymmetric catalysis. Tetrahedron Asymmetry. 2014;25(12), 923-935. doi:10.1016/ j.tetasy.2014.05.003

[21] Scettri A, Massa A, Palombi L, Villano R, Acocella MR. Organocatalytic asymmetric aza-Michael addition of aniline to chalcones under solvent-free conditions. Tetrahedron Asymmetry. 2008;19(18):2149-52. doi:10.1016/j.tetasy.2008.09.006

[22] Marcia de Figueiredo R, Mazziotta A, Pereira de Sant'Ana D, Palumbo C, Gasperi T. Active methylene compounds in asymmetric organocatalytic synthesis of natural products and pharmaceutical scaffolds. Curr Org Chem. 2012;16:2231-89.

[23] References containing "Organocatalysis" as entered. [cited 2014 Dec 15] Available from https://scifinder.cas.org/scifinder/view/ scifinder/scifinderExplore.

[24] MacMillan DWC. Commentary: the advent and development of organocatalysis. Nature. 2008;455(7211):304-08. doi:10. 1038/nature07367

[25] Bredig G, Fiske P. Biochem Z. 1912;46:7.

[26] Pracejus H. Asymmetrische Synthesen mit Ketenen, II. Stereospezifische addition von $\alpha$-Phenyl-äthylamin an Phenyl-methylketen. Justus Liebigs Ann Chem. 1960;634(1):23-29. doi:10. 1002/jlac.19606340104

[27] Hajos ZG, Parrish DR. Patent DE 2102623. 1971.

[28] Hajos ZG, Parrish DR. Patent US 3975442. 1971.

[29] Eder U, Sauer G, Wiechert R. Patent DE 2014757. 1971.

[30] Seayad J, List B. Emerging area: asymmetric organocatalysis. Org Biomol Chem. 2005;3(5):719-24. doi:10.1039/b415217b

[31] Bella M, Gasperi T. Organocatalytic formation of quaternary stereocenters. Synthesis. 2009;2009(10):1583-614. doi:10. 1055/s-0029-1216796

[32] Doyle AG, Jacobsen EN. Chem Rev. 2007;107:5713-43.

[33] Ricci A. ISRN Organic Chemistry. 2014;2014:1-29.

[34] List B, Lerner RA, Barbas CF. Proline-catalyzed direct asymmetric aldol reactions. J Am Chem Soc. 2000;122(10):2395-96. doi:10.1021/ja994280y

[35] Ishikawa H, Suzuki T, Hayashi Y. High-yielding synthesis of the anti-influenza neuramidase inhibitor (-)-oseltamivir by three "one-pot" operations. Angew Chem Int Ed. 2009;48(7):130407. doi:10.1002/anie.200804883

[36] Magano J. Synthetic approaches to the neuraminidase inhibitors zanamivir (Relenza) and oseltamivir phosphate (Tamiflu) for the treatment of influenza. Chem Rev. 2009;109(9):439838. doi: $10.1021 / \mathrm{cr} 800449 \mathrm{~m}$

[37] List B, Coric I, Grygorenko 00, Kaib PSJ, Komarov I, Lee A, Leutzsch M, Chandra Pan S, Tymtsunik AV, van Gemmeren M. The catalytic asymmetric $\alpha$-benzylation of aldehydes. Angew Chem Int Ed. 2014;53(1):282-85. doi:10.1002/anie. 201306037

[38] Marigo M, Franzén J, Poulsen TB, Zhuang W, Jørgensen KA. Asymmetric organocatalytic epoxidation of $\alpha, \beta$-unsaturated aldehydes with hydrogen peroxide. J Am Chem Soc. 2005;127 (19):6964-65. doi:10.1021/ja051808s

[39] Bondzic BP, Urushima T, Ishikawa H, Hayashi Y. Asymmetric epoxidation of $\alpha$-substituted acroleins catalyzed by diphenylprolinol silyl ether. Org Lett. 2010;12(23):5434-37. doi:10.1021/ ol102269s
[40] Abbasov ME, Romo D. The ever-expanding role of asymmetric covalent organocatalysis in scalable, natural product synthesis. Nat Prod Rep. 2014;31(10):1318-27. doi:10.1039/C4NP00 025K

[41] Holland MC, Paul S, Schweizer WB, Bergander K, MückLichtenfeld C, Lakhdar S, Mayr H, Gilmour R. Noncovalent interactions in organocatalysis: modulating conformational diversity and reactivity in the MacMillan catalyst. Angew Chem Int Ed. 2013;52(31):7967-71. doi:10.1002/anie.20130 1864

[42] Berkessel A, Gröger H. Asymmetric organocatalysis. Weinheim: Wiley-VCH; 2004.

[43] Knowles RR, Jacobsen EN. Attractive noncovalent interactions in asymmetric catalysis: links between enzymes and small molecule catalysts. Proc Nat Acad Sci. 2010;107(48):20678-85. doi:10.1073/pnas.1006402107

[44] Vakulya B, Varga S, Csámpai A, Soós T. Highly enantioselective conjugate addition of nitromethane to chalcones using bifunctional cinchona organocatalysts. Org Lett. 2005;7(10):1967-69. doi:10.1021/ol050431s

[45] Schreiner PR, Wittkopp A. H-bonding additives act like Lewis acid catalysts. Org Lett. 2002;4(2):217-20. doi:10.1021/ol01 $7117 \mathrm{~s}$

[46] Lattanzi A. Bis(3,5-dimethylphenyl)-(S)-pyrrolidin-2-ylmethanol: an improved organocatalyst for the asymmetric epoxidation of $\alpha, \beta$-enones. Adv Synth Catal. 2006;348(3):339-46. doi:10.1002/ adsc. 200505370

[47] Reddy BVS, Reddy SM, Swain M, Dudem S, Kalivendi SV, Reddy CS. Enantioselective 1,4-addition of kojic acid derivatives to $\beta$-nitroolefins catalyzed by a cinchonine derived sugar thiourea. RSC Adv. 2014;4(18):9107. doi:10.1039/c3ra47423b

[48] Siau W-Y, Wang J. Asymmetric organocatalytic reactions by bifunctional amine-thioureas. Catal Sci Technol. 2011;1(8) 1298. doi:10.1039/c1cy00271f

[49] Wittkopp A, Schreiner PR. Metal-free, noncovalent catalysis of Diels-Alder reactions by neutral hydrogen bond donors in organic solvents and in water. Chem Eur J. 2003;9(2):407-14. doi:10.1002/chem.200390042

[50] Sigman MS, Vachal P, Jacobsen EN. A general catalyst for the asymmetric Strecker reaction. Angew Chem Int Ed. 2000; 39(7):1279-81. doi:10.1002/(SICI)1521-3773(20000403)39: 7<1279::AID-ANIE1279>3.0.CO;2-U

[51] Pihko PM. Activation of carbonyl compounds by double hydrogen bonding: an emerging tool in asymmetric catalysis. Angew Chem Int Ed. 2004;43(16):2062-64. doi:10.1002/ anie.200301732

[52] Ema T, Tanida D, Matsukawa T, Sakai T. Biomimetic trifunctional organocatalyst showing a great acceleration for the transesterification between vinyl ester and alcohol. Chem Commun. 2008;(8):957-59. doi:10.1039/b718763g

[53] Schreiner PR. Metal-free organocatalysis through explicit hydrogen bonding interactions. Chem Soc Rev. 2003;32 (5):289. doi:10.1039/b107298f

[54] Taylor MS, Jacobsen EN. Asymmetric catalysis by chiral hydrogen-bond donors. Angew Chem Int Ed. 2006;45(10): 1520-43. doi:10.1002/anie.200503132

[55] Uyeda C, Jacobsen EN. Enantioselective Claisen rearrangements with a hydrogen-bond donor catalyst. J Am Chem Soc. 2008;130(29):9228-29. doi:10.1021/ja803370x

[56] Raheem IT, Thiara PS, Peterson EA, Jacobsen EN. Enantioselective Pictet-Spengler-type cyclizations of hydroxylactams: H-bond donor catalysis by anion binding. J Am Chem Soc. 2007;129(44):13404-05. doi:10.1021/ja076179w

[57] Zuend SJ, Jacobsen EN. Mechanism of amido-thiourea catalyzed enantioselective imine hydrocyanation: transition state 
stabilization via multiple non-covalent interactions. J Am Chem Soc. 2009;131(42):15358-74. doi:10.1021/ja9058958

[58] Li Y-M, Li X, Peng F-Z, Li Z-Q, Wu S-T, Sun Z-W, Zhang H-B, Shao Z-H. Org Lett. 2011;13(23):6200-03. doi:10.1021/ol20 $2624 \mathrm{f}$

[59] Yeung CS, Ziegler RE, Porco JA, Jacobsen EN. Catalytic asymmetric construction of spirocyclopentaneoxindoles by a combined Ru-catalyzed cross-metathesis/double Michael addition sequence. J Am Chem Soc. 2014;136(39):13614-17. doi:10. 1021/ja508523g

[60] Fang X, Wang C-J. Recent advances in asymmetric organocatalysis mediated by bifunctional amine-thioureas bearing multiple hydrogen-bonding donors. Chem Comm. 2015;51(7): 1185-97. doi:10.1039/C4CC07909D.

[61] Adamo MF, Aggarwal V. Epoxidation process using amine catalysts. EP1147099 A1, filed January 28, 2000.

[62] Kim J, Singaram B. Enantioselective reduction of aliphatic ketones using $\mathrm{NaBH}_{4}$ and TarB- $\mathrm{NO}_{2}$, a chiral boronic ester. Tetrahedron Lett. 2006;47(23):3901-03. doi:10.1016/j.tetlet. 2006.03.162

[63] Juhl K, Jørgensen KA. The first organocatalytic enantioselective inverse-electron-demand Hetero-Diels-Alder reaction. Angew Chem Int Ed. 2003;42(13):1498-501. doi:10.1002/anie.2002 50652

[64] Hayashi Y, Samanta S, Itoh T, Ishikawa H. Asymmetric, catalytic, and direct Self-Aldol reaction of acetaldehyde catalyzed by diarylprolinol. Org Lett. 2008;10(24):5581-83. doi:10.1021/ol802438u

[65] Meninno S, Lattanzi A. Asymmetric organocatalysis mediated by $\alpha, \alpha$-L-diaryl prolinols: recent advances. Chem Comm. 2013;49(37):3821. doi:10.1039/c3cc36928e

[66] Fang L, Lin A, Jia X, Meng J, Wang Y, Zhu C. Diarylprolinols. Lett Org Chem. 2009;6:397.

[67] Zheng C, Li Y, Yang Y, Wang H, Cui H, Zhang J, Zhao G. Highly efficient asymmetric epoxidation of electron-deficient $\alpha, \beta$-enones and related applications to organic synthesis. Adv Synth Cat. 2009;351(10):1685-91. doi:10.1002/adsc.200900041

[68] Lattanzi A. Enantioselective epoxidation of $\alpha, \beta$-enones promoted by $\alpha, \alpha$-diphenyl-l-prolinol as bifunctional organocatalyst. Org Lett. 2005;7(13):2579-82. doi:10.1021/ol050694m

[69] De Fusco C, Tedesco C, Lattanzi A. Organocatalytic stereoselective epoxidation of trisubstituted acrylonitriles. J Org Chem. 2011;76(2):676-79. doi:10.1021/jo102020a

[70] Palumbo C, Mazzeo G, Mazziotta A, Gambacorta A, Loreto MA, Migliorini A, Superchi S, Tofani D, Gasperi T. Noncovalent organocatalysis: a powerful tool for the nucleophilic epoxidation of $\alpha$-ylideneoxindoles. Org Lett. 2011;13(23):6248-51. doi:10.1021/ol202646w

[71] Capobianco A, Russo A, Lattanzi A, Peluso A. On the mechanism of asymmetric epoxidation of enones catalyzed by $\alpha, \alpha-\mathrm{L}-$ diarylprolinols: a theoretical insight. Adv Synth Catal. 2012;354(14-15):2789-96. doi:10.1002/adsc.201200415

[72] Fleischmann M, Drettwan D, Sugiono E, Rueping M, Gschwind RM. Brønsted acid catalysis: hydrogen bonding versus ion pairing in imine activation. Angew Chem Int Ed. 2011;50(28): 6364-69. doi:10.1002/anie.201101385

[73] Kwan EE. The rate of proton transfer. J Chem Ed. 2007;84 (1):39. doi:10.1021/ed084p39

[74] Ault A. Telling it like it is: teaching mechanisms in organic chemistry. J Chem Ed. 2010;87(9):937-41. doi:10.1021/ed10 0345k

[75] Anastas P, Eghbali N. Green chemistry: principles and practice. Chem Soc Rev. 2010;39(1):301-12. doi:10.1039/B918763B

[76] Čorić I. Asymmetric Brønsted acid catalysis: acetals \& confined catalysts [PhD dissertation]. Universität zu Köln; 2012.
[77] Akiyama T, Itoh J, Yokota K, Fuchibe K. Enantioselective Mannich-type reaction catalyzed by a chiral Brønsted acid. Angew Chem Int Ed. 2004;43(12):1566-68. doi:10.1002/anie. 200353240

[78] Uraguchi D, Terada M. Chiral Brønsted acid-catalyzed direct Mannich reactions via electrophilic activation. J Am Chem Soc. 2004;126(17):5356-57. doi:10.1021/ja0491533

[79] Kampen D, Reisinger C, List B. Chiral Brønsted acids for asymmetric organocatalysis. In: List B, editor. Asymmetric organocatalysis. Heidelberg: Springer-Verlag Berlin Heidelberg; 2009. p. 1-37.

[80] Bergonzini G, Gramigna L, Mazzanti A, Fochi M, Bernardi L, Ricci A. Organocatalytic asymmetric Povarov reactions with 2and 3-vinylindoles. Chem Comm. 2010;46(2):327-29. doi:10. 1039/B921113F

[81] Coric I, Kim JH, Vlaar T, Patil M, Thiel W, List B. Brønsted acid catalyzed asymmetric SN2-type 0-alkylations. Angew Chem Int Ed. 2013;52(12):3490-93. doi:10.1002/anie.201209983

[82] Duce S, Pesciaioli F, Gramigna L, Bernardi L, Mazzanti A, Ricci A, Bartoli G, Bencivenni G. An easy entry to optically active spiroindolinones: chiral Brønsted acid-catalysed Pictet-Spengler reactions of isatins. Adv SynthCatal. 2011;353(6):860-64. doi:10.1002/adsc.201100050

[83] De CK, Pesciaioli F, List B. Catalytic asymmetric benzidine rearrangement. Angew Chem. 2013;125(35):9463-65. doi: 10.1002/ange.201304039

[84] Vellalath S, Coric I, List B. N-Phosphinyl phosphoramide-a chiral Brønsted acid motif for the direct asymmetric N,Oacetalization of aldehydes. Angew Chem Int Ed. 2010;122 (50):9943-46. doi:10.1002/ange.201005347

[85] Cheng X, Vellalath S, Goddard R, List B. Direct catalytic asymmetric synthesis of cyclic aminals from aldehydes. J Am Chem Soc. 2008;130(47):15786-87. doi:10.1021/ja8071034

[86] Čorić I, Vellalath S, List B. Catalytic asymmetric transacetalization. J Am Chem Soc. 2010;132(25):8536-37. doi:10.1021/ ja102753d

[87] Rowland GB, Zhang H, Rowland EB, Chennamadhavuni S, Wang Y, Antilla JC. Brønsted acid-catalyzed imine amidation. J Am Chem Soc. 2005;127(45):15696-97. doi:10.1021/ja0 533085

[88] Zhuang M, Du H. Chiral Brønsted acid catalyzed enantioselective intermolecular allylic aminations. Org Biomol Chem. 2014;12(26):4590. doi:10.1039/c4ob00526k

[89] Kötzner L, Webber MJ, Martínez A, De Fusco C, List B. Asymmetric catalysis on the nanoscale: the organocatalytic approach to helicenes. Angew Chem Int Ed. 2014;53:5202.

[90] Čorić I, Müller S, List B. Kinetic resolution of homoaldols via catalytic asymmetric transacetalization. J Am Chem Soc. 2010;132(49):17370-73. doi:10.1021/ja108642s

[91] Xu F, Huang D, Han C, Shen W, Lin X, Wang Y. SPINOL-derived phosphoric acids: synthesis and application in enantioselective Friedel-Crafts reaction of indoles with imines. J Org Chem. 2010;75(24):8677-80. doi:10.1021/jo101640z

[92] Coric I, List B. Asymmetric spiroacetalization catalysed by confined Brønsted acids. Nature. 2012;483(7389):315-19. doi:10.1038/nature10932

[93] Liao S, Čorić I, Wang Q, List B. Activation of $\mathrm{H}_{2} \mathrm{O}_{2}$ by chiral confined Brønsted acids: a highly enantioselective catalytic sulfoxidation. J Am Chem Soc. 2012;134(26):10765-68. doi:10.1021/ja3035637

[94] Kim JH, Coric I, Vellalath S, List B. The catalytic asymmetric acetalization. Angew Chem Int Ed. 2013;52(16):4474-77. doi:10.1002/anie.201300120

[95] Shaikh IR. Organocatalysis: key trends in green synthetic chemistry, challenges, scope towards heterogenization, and 
importance from research and industrial point of view. J Catalysts. 2014;2014:1.

[96] List B, Lee J-W, Mayer-Gall T, Opwis K, Gutmann JS. Patent EP20120170144, 2012.

[97] Lee J-W, Mayer-Gall T, Opwis K, Song CE, Gutmann JS, List B. Organotextile catalysis. Science. 2013;341(6151):1225-29. doi:10.1126/science.1242196

[98] Newland SH, Xuereb DJ, Gianotti E, Marchese L, Rios R, Raja R. Highly effective design strategy for the heterogenisation of chemo- and enantioselective organocatalysts. Catal Sci Technol. 2015;5(2):660-65. doi:10.1039/C4CY00895B.

[99] Chiroli V, Benaglia M, Puglisi A, Porta R, Jumde RP, Mandoli A. A chiral organocatalytic polymer-based monolithic reactor. Green Chem. 2014;16(5):2798. doi:10.1039/c4gc00031e

[100] Goldys AM, Núñez MG, Dixon DJ. Creation through immobilization: a new family of high performance heterogeneous bifunctional iminophosphorane (BIMP) superbase organocatalysts. Org Lett. 2014;16(24):6294-97. doi:10.1021/ ol5029942

[101] Rostamnia S, Doustkhah E. Nanoporous silica-supported organocatalyst: a heterogeneous and green hybrid catalyst for organic transformations. RSC Adv. 2014;4(54):28238. doi:10. 1039/c4ra03773a

[102] Gurka A, Bucsi I, Kovács L, Szollosi G, Bartók M. Reversal of the enantioselectivity in aldol addition over immobilized di- and tripeptides: studies under continuous flow conditions. RSC Adv. 2014;4(106):61611-18. doi:10.1039/C4RA07188C

[103] Rawat V, Dey S, Shelke AM, Suryavanshi GM, Arumugam S. Organocatalytic process for asymmetric synthesis of decanolides, patent WO2014037964A2, 2014.

[104] Garrett RC, Yang H. Patent US 8399684 B2, 2013.

[105] Verma RS, Polshettiwar V. Patent US 8324125 B2. 2012.

[106] Cordova A, Hafren J. Patent WO 2006068611. 2006.
[107] Davis TA, Vilgelm AE, Richmond A, Johnston JN. J Org Chem. 2013;78(21):10605-16. doi:10.1021/jo401321a

[108] Blaser HU, Federsel H-J. (Eds.). Asymmetric catalysis on industrial scale: challenges, approaches and solutions. Weinheim: Wiley-VCH; 2010.

[109] Dalko PI. (Ed.). Comprehensive enantioselective organocatalysis: catalysts, reactions, and applications. Weinheim: WileyVCH; 2013.

\section{COMPETING INTERESTS}

The authors declare no competing interests.

\section{PUBLISHING NOTES}

(C) 2015 C. Palumbo and M. Guidotti. This work has been published open access under Creative Commons Attribution License CC BY 4.0, which permits unrestricted use, distribution, and reproduction in any medium, provided the original work is properly cited. Conditions, terms of use and publishing policy can be found at www.scienceopen.com.

Please note that this article may not have been peer reviewed yet and is under continuous post-publication peer review. For the current reviewing status please click here or scan the QR code on the right.

\section{scienceOPEN.com}

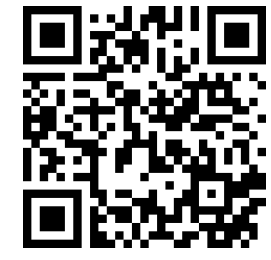

